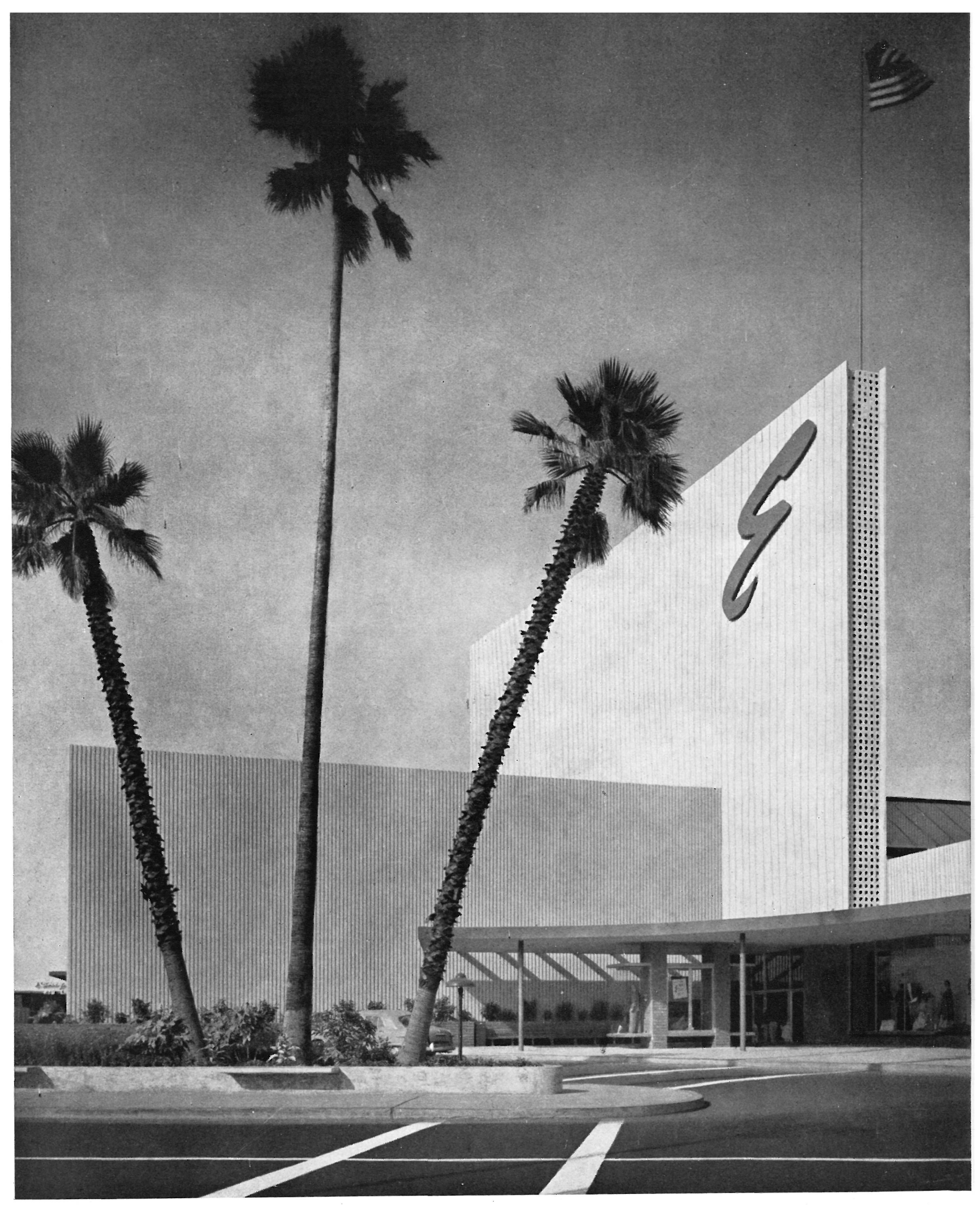

$134-5$

\title{
centro comercial de Stonestown
}




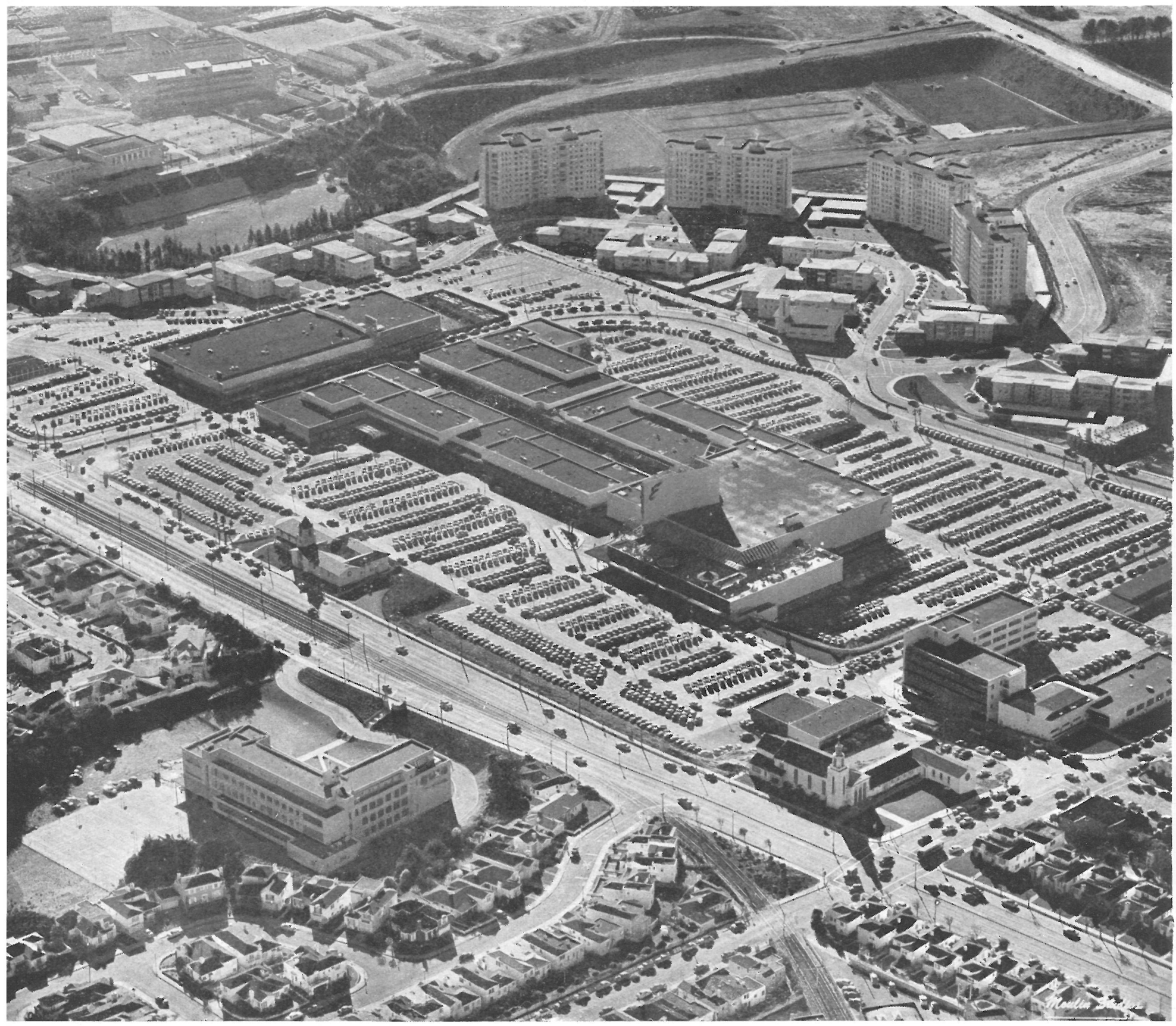

El hombre tiene unas tendencias y unas necesidades. Unas y otras ha de satisfacerlas en la sociedad de la que es parte. Esta, $\Rightarrow$ traves de sus elementos y organismos directores, debe procurar manera que sus componentes todos, encuentren marco adecuado para ello, es decir, que facilite sus cotidianos menesteres, que haga su vida alegre y en el cual no sólo sea posible y fácil el desarrollo de la personalidad de cada uno, sino que éste se vea estimulado.

La sociedad es una "cosa» viva, y como tal se transforma y modifica al influir en ella factores nuevos o resucitados.

Comprar y vender, cuidar la salud, charlar, tener una cosa y procurarse bienestar y distracción... parece ser una necesidad de todos los tiempos. Se compra, y como consecuencia ineludible se vende, en las tiendas y en sus hermanos mayores los. alma-
cenes. Se charla en los cafés, lugares de reunión, etc. Se busca distracción en el cine, en los libros y en cien sitios más. Se cuida la salud en las clínicas o en sanatorios.

La actual ciudad es un gigante, que subsiste gracias a los medios de comunicación rápidos y a la producción en serie de automoviles. La circulacion, en sus centros y barrios comerciales antiguos ayer tranquilos, es hoy fabulosa e impide aparcar mientras se realizan las compras.

Agrupar todos estos servicios en lugar apropiado que permita realizar grandes aparcamientos y descongestionar el centro de la ciudad son, en síntesis, los motivos que han llevado a la

El gran "centro comercial de Stonestown», situado en las afueras de San Francisco, es un buen ejemplo, ya que ha de satisfacer las necesidades de 400.000 habitantes y su radio de 


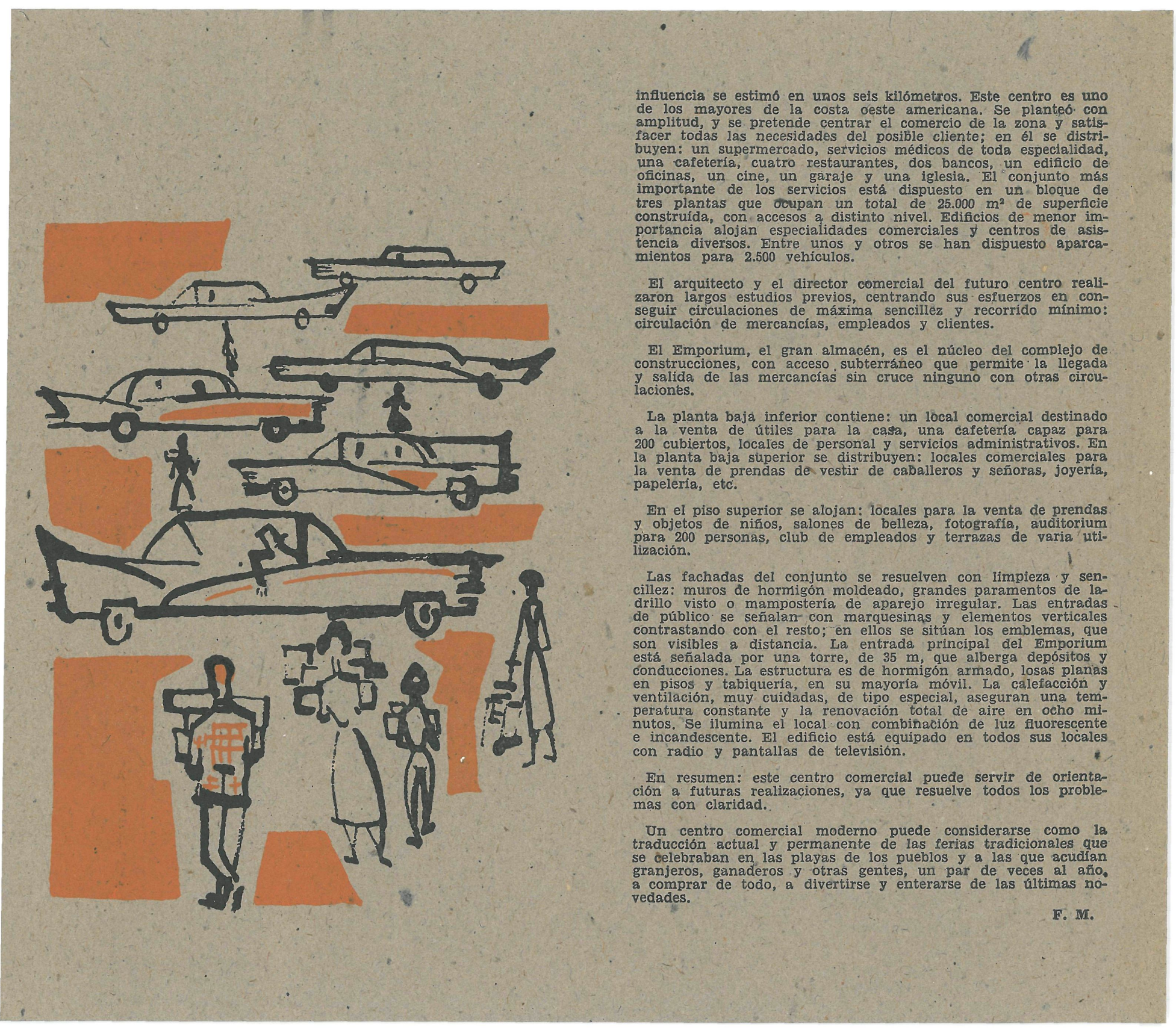




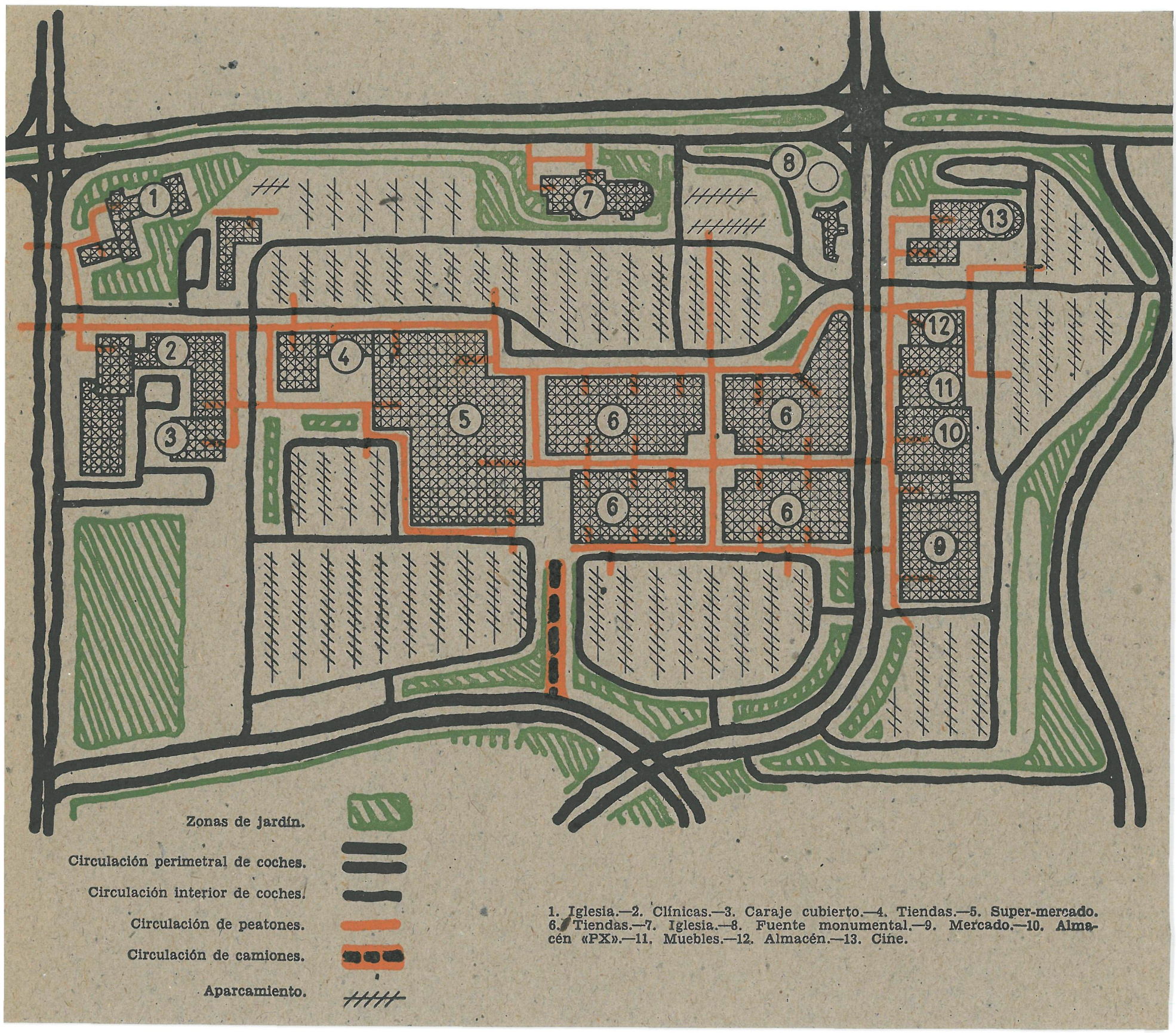




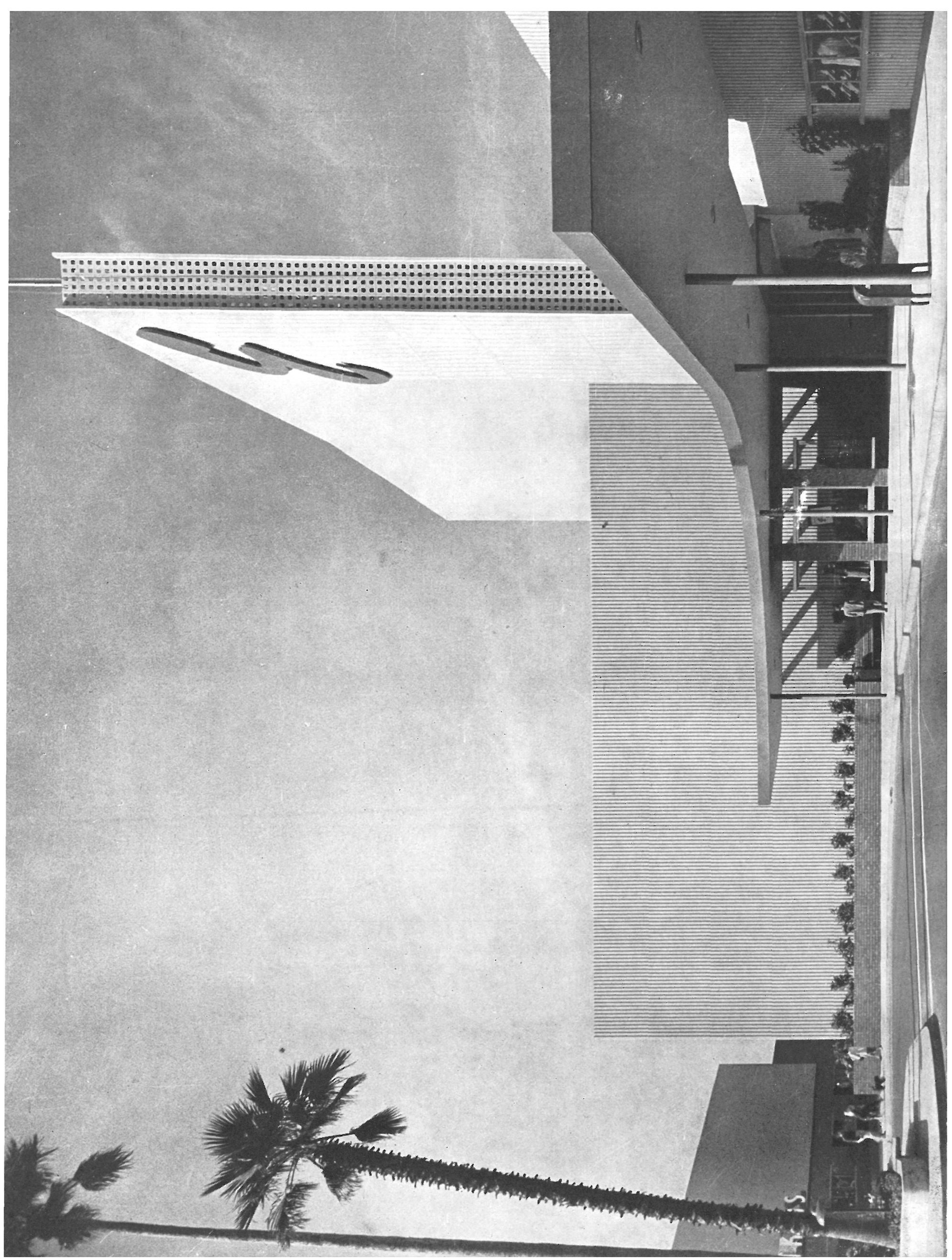




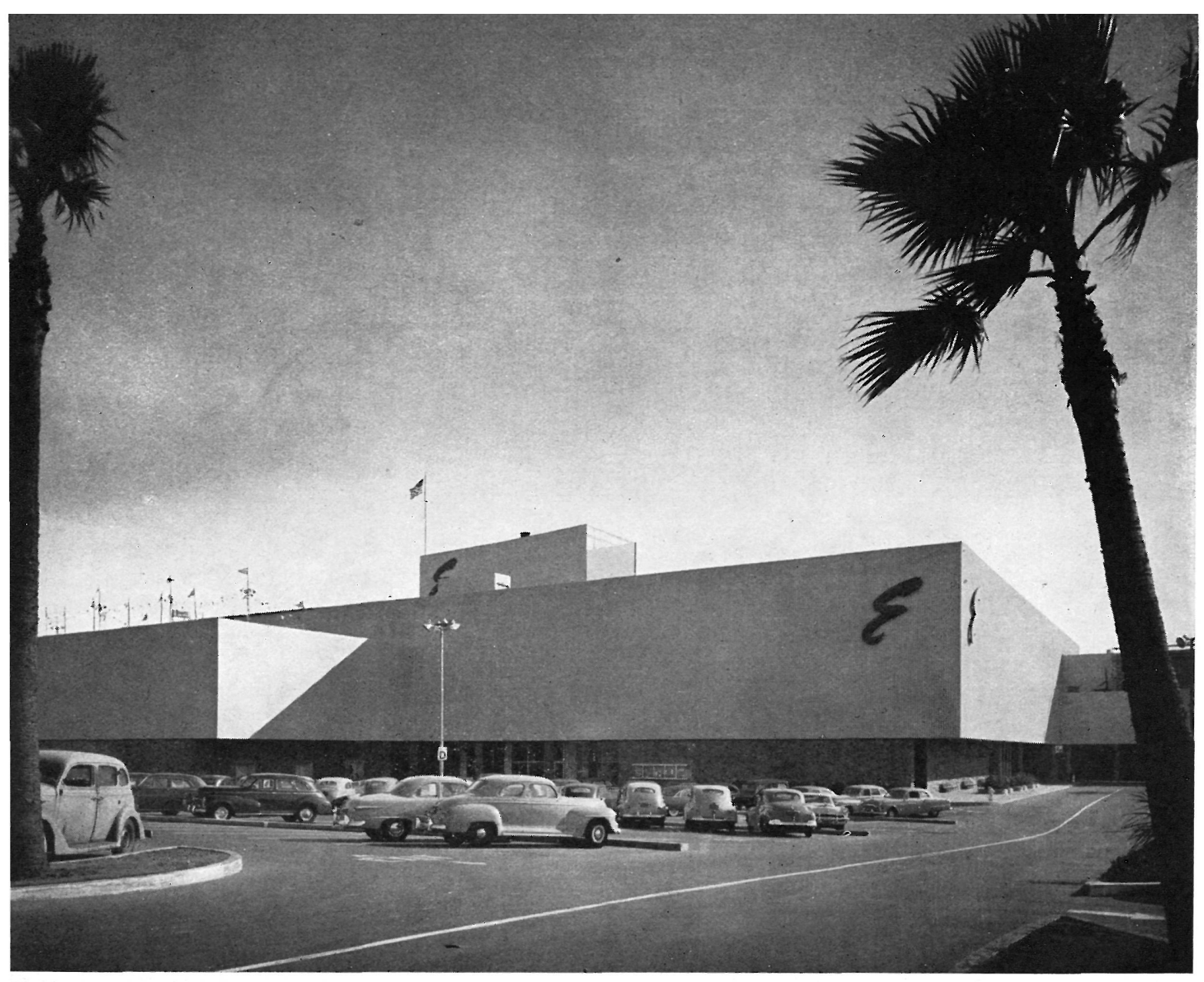

exteriores

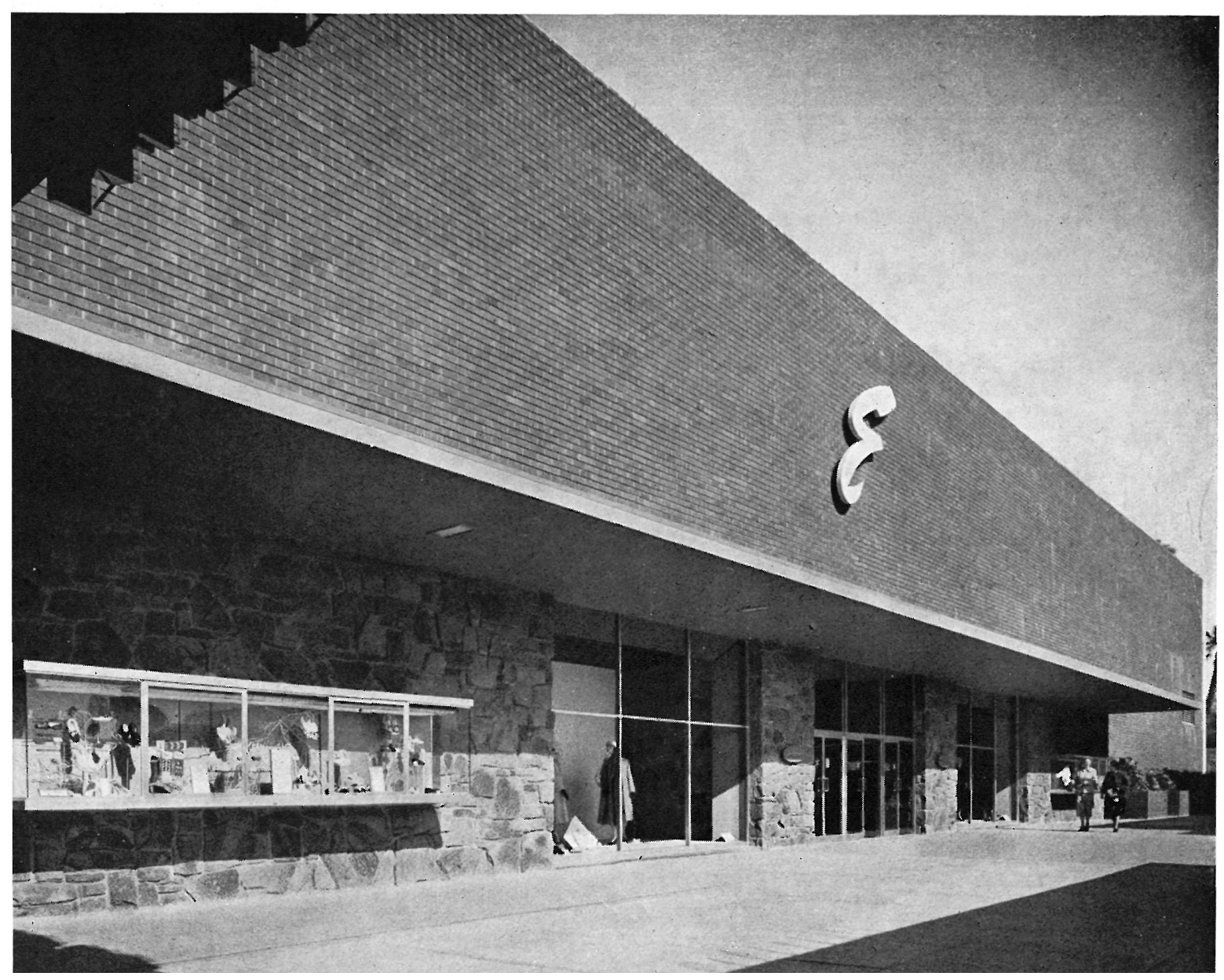

Fotos: ROBERT C. CLEVELAND 